JIOM Nepal. Volume 41 Number 3. December 2019, page 63-66.

\title{
Outcome of Endoscopic Sphenopalatine Artery Cauterization for Posterior Epistaxis
}

\author{
Bijaya Kharel, Urmila Gurung, Prashant Tripathi, Pabina Rayamajhi, Priyansha Silwal \\ Department of ENT, Maharajgunj Medical Campus, Ganesh Man Singh Memorial Academy of ENT-Head \& Neck \\ Surgery, Institute of Medicine, Kathmandu, Nepal
}

\section{Corresponding author:}

\section{Urmila Gurung, MBBS, MS}

Department of ENT, Maharajgunj Medical Campus, Ganesh Man Singh Memorial Academy of ENT-Head \& Neck Surgery, Institute of Medicine, Kathmandu, Nepal

Email:dr.urmila.gurung@gmail.com

Submitted : November 5, 2019

Accepted : December 4, 2019

\begin{abstract}
\section{Introduction}

Epistaxis is a common otorhinolaryngology emergency condition. Majority of it is anterior epistaxis which usually improves with conservative management. However, for posterior epistaxis, apart from posterior nasal packing, endoscopic sphenopalatine artery cauterization (ESPAC) is considered an effective measure for its control. Hence, this study was conducted to evaluate the outcome of endoscopic sphenopalatine artery cauterization for posterior epistaxis.
\end{abstract}

\section{Methods}

Retrospective medical chart review of patients who underwent endoscopic sphenopalatine artery cauterization for posterior epistaxis from January to December 2018 at Ganesh Man Singh Memorial Academy of ENT-Head \& Neck Surgery, Tribhuvan University Teaching Hospital, Kathmandu, Nepal.

\section{Results}

A total of 31 patients (21 males and 10 females) underwent ESPAC during the one-year period. Twentyseven of them were unilateral whilst four were bilateral. Four of them rebled, of which two bled within 48 hours and the remaining two after two months. The overall success rate of ESPAC was 87.1\% (27/31).

\section{Conclusion}

Endoscopic sphenopalatine artery cauterization is an effective measure to control posterior epistaxis.

Keywords: Endoscopy, epistaxis, nasal packing, sphenopalatine artery cauterization

\section{INTRODUCTION}

E pistaxis is a common otorhinolaryngology emergency that may require hospital admission. Its prevalence is estimated to be $10-12 \%$, of which $10 \%$ seek medical attention and $1 \%$ will require surgical intervention. ${ }^{1}$ Up to $90 \%$ of epistaxis arises from Littles area (Kiesselbach plexus) which are easily accessible and can be controlled with chemical cautery, packing or other conservative methods. However, in $10 \%$ of epistaxis, bleeding occurs from the posterior nasal cavity which is difficult to access and may require more aggressive interventions. ${ }^{2}$ About 5 to $15 \%$ of these patients require some form of surgical treatment either interruption or occlusion of the main feeding vessel if the bleeding continues despite repeated packing. ${ }^{3,4,5}$ Risk factors such as hypertension, arteriosclerosis, diabetes, NSAIDS have unfavorable outcome like rebleed inspite of the surgical treatment. ${ }^{6}$ The significant predictors for surgical treatment are persistent posterior bleed, low hemoglobin and hematocrit less than $38 \%$ and the need for blood transfusion. ${ }^{6,7}$

Sphenopalatine artery, the terminal branch 
of the maxillary artery, is also the main blood supply to the posterior nasal cavity. ${ }^{7}$ Endoscopic sphenopalatine artery cauterization (ESPAC) has emerged as the surgical procedure of choice as compared to conventional external carotid and maxillary artery ligation for refractory epistaxis because it addresses the most distal blood supply to the nasal cavity and also has excellent efficacy with minimal morbidity. ${ }^{3,8}$

This study primarily aimed to evaluate the effectiveness of ESPAC in controlling posterior epistaxis. It further investigated the risk factors associated with the epistaxis and the need for additional procedure such as septoplasty, anterior ethmoidal artery ligation, postoperative nasal packing in addition to ESPAC.

\section{METHODS}

This was a retrospective chart review of posterior epistaxis patients who underwent ESPAC either under general or local anesthesia from 1st January to 31st December 2018 at Ganeshman Man Singh Memorial Academy of ENT- Head and Neck Studies, Tribhuvan University Teaching Hospital (TUTH), Kathmandu, Nepal. Patients' demographics, co-morbidities, type and duration of nasal packing, surgical procedure - unilateral or bilateral, the anesthesia type, the operator grade, any additional procedures and rebleed events were noted. Patients with missing clinical notes on rebleed events were contacted via telephone regarding any rebleed events.

The data were entered in Microsoft Excel (16 version). The frequencies and mean were calculated.

\section{RESULTS}

A total of 31 patients (21 male:10 female) underwent ESPAC for epistaxis management during the one year period. The age ranged from 20 to 79 years with the mean being 53.25 years There were 26 (83.87\%) unilateral nasal bleeding and $5(16.12 \%)$ bilateral nasal bleeding.

Hypertension was found to be the most common comorbid condition amounting to $41.9 \%$ (13/31) of the cases. It was found as a single comorbidity in $8 / 31$ (25.8\%). Amongst the five who had other associated co-morbidities along with hypertension, two had diabetes mellitus (DM), one each had DM with previous cardiac surgery, DM with seizure disorder, currently on aspirin due to stroke in the past. Two patients had DM as single co-morbidity. None of them had preceding trauma for epistaxis except for 1 rebleed case who had repeated nose pricking.
Table 1. Various type of nasal pack used for packing

\begin{tabular}{lc}
\hline \multicolumn{1}{c}{ Type of nasal pack } & $\begin{array}{c}\text { Cases } \\
(\mathbf{n})\end{array}$ \\
\hline Rapid Rhino@ (Applied Therapeutics, UK) & 15 \\
Bismuth lodoform paraffin paste pack & 4 \\
Merocele@ (Medtronic Xomed, FL, USA) & 2 \\
Invotec $($ Invotec International Inc., USA) & 2 \\
Foleys (in referred case) & 2 \\
None & 6 \\
\hline
\end{tabular}

There were no identifiable co-morbidities in 16/31 $(51.6 \%)$ cases.

Fifteen out of 31 (48.4\%) cases were packed with Rapid Rhino ${ }^{\circledR}$ inflatable balloon catheter. Ten had other packing materials were used (Table 1). The two cases who had Foley's catheter placed were referred from other centers.

The duration of nasal packing varied from 3 days to maximum of 9 days. In 9/31 (29.03\%) cases surgical intervention was done within 3 days of packing. 22/31 (70.96\%) patients had nasal packing more than 3 days.

Twenty-seven out of $31(87.09 \%)$ had unilateral whilst 4/31 (12.91\%)had bilateral ESPAC.

There were 28 cases performed under GA and 3 cases under $L A$.

Twenty out of 31 cases (64.51\%) were operated by faculty/consultant whilst the remaining 11 $(35.48 \%)$ were performed by residents under supervision of faculty/consultant.

Additional procedures were done in 13 cases which consisted of middle meatal antrostomy in 5 , septoplasty in 4, septoplasty with bilateral flap elevation in 2, endoscopic sinus surgery (ESS) and inferior turbinate reduction in one each.

The overall success rate of ESPAC was 87.1 $\%$ (27/31) with 4 rebleed cases. Out of the 4, 2 rebled within 48 hours and were managed conservatively with medical management without nasal packing. In one of the two cases, there was both hypertension and diabetes as risk factor along with use of aspirin 3 days prior to surgery.

Remaining two bled after 2 months, one due to excessive crusting and the other due to upper respiratory tract infection. Both of them were admitted and managed medically without any further packing or surgical intervention. No comorbidities were found in either cases. However, an additional procedure namely maxillary antrostomy was done in 1 case that resulted in crusting and infection and subsequent rebleed. 
Table 2. Success rate with complications in other studies

\begin{tabular}{lccc}
\hline \multicolumn{1}{c}{ Study } & Patients (n) & Effectiveness & Complication \\
\hline Holzman et al & & & $16 \%$ \\
Gandomi et al $^{16}$ & 75 & $96 \%$ & 0 \\
Snyderman et al $^{17}$ & 27 & $87 \%$ & $53 \%$ \\
O'flynn et al $^{10}$ & 42 & $88 \%$ & 0 \\
Wormald et al $^{18}$ & 12 & $88 \%$ & 0 \\
Agreda et al & 13 & $92 \%$ & - \\
\hline
\end{tabular}

\section{DISCUSSION}

Recurrent epistaxis remains a significant cause of morbidity posing as a challenge to an otorhinolaryngologist. Risk factors for recurrent epistaxis are elderly patients with co-morbidities such as hypertension, arteriosclerosis, diabetes, coagulopathy, alcohol and tobacco use, patients on anticoagulants and non-steroidal antiinflammatory drugs (NSAIDs). ${ }^{6}$ Such risk factors have unfavorable outcomes in both surgical and non-surgical treatment. ${ }^{9}$ The occurrence of comorbidities ranges from 30 to $50 \%$ in different studies. $3,7,10$ This is similar to our study where $15 / 31$ $(48.38 \%)$ had co-morbidities with hypertension being the commonest.

In our study, 22/31 (70.96\%) patients had nasal packing more than 3 days. The departmental policy is to keep double balloon catheter for 72 hours. The cuff is deflated for an hour with the pack still in situ. If bleeding persists, the cuff is re-inflated and the similar procedure repeated on a daily basis till patient has no bleed when the cuff is deflated or when the patient can be listed for ESPAC at the earliest. Since we have limited operative slot for the procedure, this has resulted in patients having nasal packing more than 3 days. All patient needing nasal packing were kept under antibiotics.

Nasal packing is the conventional management for posterior epistaxis, however, it can be associated with extreme pain, discomfort, skin and mucosal necrosis, breathing difficulties, syncope, hypoxia and toxic shock syndrome. ${ }^{4,11}$ Its failure rate in controlling the posterior epistaxis ranges from $26 \%$ to $52 \% .{ }^{4}$ So, in the recent years, the preference has shifted to endoscopic sphenopalatine artery ligation or cauterization as first line treatment for posterior epistaxis. 3,11,12

Endoscopic endonasal ligation of the SPA was first described by Budrovich et al in 1992.13 Over the years, it has replaced the traditional approaches namely internal maxillary artery and external carotid artery ligation. ESPAC has been shown to be associated with a shorter hospital stay and is cost effective compared to other surgical modalities. ${ }^{1,7}$ There are no contraindications for SPA cauterization. ${ }^{4}$ It can be used for the control of posterior epistaxis as an immediate second-line management when conservative treatment as first line fails as it is safe, effective and well tolerated. 3,5,12 Some authors even consider this as a first line of management instead of packing. 3,11,12,14,15

Endoscopic sphenopalatine artery ligation or cauterization is effective with success rate ranging from $84-100 \%, 3,7,10,11,12,16,17,18$ Our result was similar with $87.1 \%$ success rate. Published data shows no difference in outcome among the ligation, monopolar or bipolar group.3,9,12 However, many authors advocate coagulation diathermy over ligation only to avoid early bleeding due to inaccurate clipping or slippage of ligature. 3,11

ESPAC failure ranges from 0-16\%. 4,6,10,11,16,17,18 The reasons as listed by Thakkar et al., include cross anastomosis, dominant contralateral internal maxillary artery and failure to identify and ligate all branches. ${ }^{19}$ As per $O$ Flynn et al., multiple branching of the SPA and the variations in the anatomical landmarks could contribute to failure. ${ }^{10}$ Use of aspirin or warfarin, low platelet count on admission also might lead to early failure. ${ }^{3}$

In our study, 4 rebled of which 2 bled within 48 hours. These patients probably had multiple branches of SPA however SPA branches were not made note of in this study. One rebleed case had middle meatal antrostomy additionally which lead to crusting and infection subsequently leading to rebleed. Bilateral ESPAC probably prevented cross anastomosis hence none of them rebled.

There are some likely minor complications after ESPAC including increased nasal crusting, palatal numbness, facial paresthesia and sinusitis ranging from 16 to 53\% (Table 2).4,6,9,11,17 As per Synderman et al., these early complications are mild, transient and self limiting. ${ }^{17}$

This study has some limitations. These include the retrospective nature of the study, the limited sample size and the procedure being performed by multiple surgeons. A prospective study involving a larger sample size and longer follow 
up is recommended to asses the effectiveness of ESPAC in posterior epistaxis.

\section{CONCLUSION}

Endoscopic sphenopalatine artery cauterization can be used as an alternative effective measure to control posterior epistaxis when other methods fail.

\section{CONFLICT OF INTEREST}

None declared.

\section{REFERENCES}

1. Rockey JG, Anand R. A critical audit of the surgical management of intractable epistaxis using sphenopalatine artery ligation/diathermy. Rhinology. 2002 Sep 1;40(3):147-9.

2. Bolger WE, Borgie RG, Melder P. The Role of the Crista Ethmoidalis in Endoscopic Sphenopalatine Artery Ligation. Am J Rhinol. 1999 Mar 1;13(2):816.

3. Nouraei SAR, Maani T, Hajioff D, Saleh HA, Mackay IS. Outcome of Endoscopic Sphenopalatine Artery Occlusion for Intractable Epistaxis: A 10-Year Experience. The Laryngoscope. 2007 Aug;117(8):1452-6.

4. Gandomi B, Arzaghi MH, Khademi B, Rafatbakhsh M. Endoscopic cauterization of the sphenopalatine artery to control severe and recurrent posterior epistaxis. Iranian journal of otorhinolaryngology. 2013 Jun;25(72):147.

5. Abdelkader M, Leong SC, White PS. Endoscopic control of the sphenopalatine artery for epistaxis: long-term results. The Journal of Laryngology \& Otology. 2007 Aug;121(8):759-62.

6. Holzmann D, Kaufmann T, Pedrini P, Valavanis A. Posterior epistaxis: endonasal exposure and occlusion of the branches of the sphenopalatine artery. European archives of oto-rhinolaryngology. 2003 Sep 1;260(8):425-8.

7. McDermott AM, O'Cathain E, Carey BW, O'Sullivan P, Sheahan P. Sphenopalatine Artery Ligation for Epistaxis: Factors Influencing Outcome and Impact of Timing of Surgery. Otolaryngol Neck Surg. 2016 Mar;154(3):547-52.

8. Hey SY, Koo Ng NKF, McGarry GW. Endoscopic Sphenopalatine Artery Ligation: General
Applicability in a Teaching Unit. Ear Nose Throat J. 2019 Feb;98(2):85-8.

9. Barlow DW, Deleyiannis FW, Pinczower EF. Effectiveness of surgical management of epistaxis at a tertiary care center. The Laryngoscope. 1997 Jan;107(1):21-4.

10. O'flynn PE, Shadaba A. Management of posterior epistaxis by endoscopic clipping of the sphenopalatine artery. Clinical Otolaryngology \& Allied Sciences. 2000 Oct;25(5):374-7.

11. Agreda B, Urpegui Á, Alfonso Jl, Valles $H$. Ligation of the sphenopalatine artery in posterior epistaxis. Retrospective study of 50 patients. Acta Otorrinolaringologica (English Edition). 2011 May $1 ; 62(3): 194-8$.

12. Odat $H$, Al-Qudah M. Endoscopic monopolar cauterization of the sphenopalatine artery: a single surgeon's experience. Annals of Saudi medicine. 2016 Nov;36(6):422-6.

13. Budrovich R, Saetti E. Microscopic and endoscopic ligature of the sphenopalatine artery. The Laryngoscope. 1992 Dec;102(12):1390-4.

14. Sireci F, Speciale R, Sorrentino R, Turri-Zanoni M, Nicolotti M, Canevari FR. Nasal packing in sphenopalatine artery bleeding: therapeutic or harmful? European Archives of Oto-RhinoLaryngology. 2017 Mar 1;274(3):1501-5.

15. Paul J, Kanotra SP, Kanotra S. Endoscopic management of posterior epistaxis. Indian Journal of Otolaryngology and Head \& Neck Surgery. 2011 Apr 1;63(2):141-4.

16. Sharp HR, Rowe-Jones JM, Biring GS, Mackay IS. Endoscopic ligation or diathermy of the sphenopalatine artery in persistent epistaxis. The Journal of Laryngology \& Otology. 1997 Nov;111(11):1047-50.

17. Snyderman $\mathrm{CH}$, Goldman $\mathrm{SA}$, Carrau RL, Ferguson BJ, Grandis JR. Endoscopic sphenopalatine artery ligation is an effective method of treatment for posterior epistaxis. American journal of rhinology. 1999 Mar;13(2):137-40.

18. Wormald PJ, Wee DT, van Hasselt CA. Endoscopic ligation of the sphenopalatine artery for refractory posterior epistaxis. American journal of rhinology. $2000 \mathrm{Jul} ; 14(4): 261-4$.

19. Thakar A, Sharan CJ. Endoscopic sphenopalatine artery ligation for refractory posterior epistaxis. Indian Journal of Otolaryngology and head and neck surgery. 2005 Jul 1;57(3):215-8. 